\title{
Managing CBRN Mass Casualty Incidents at Hospitals - Find a Simple Solution for a Complex Problem: a Pilot Study
}

\section{Maximilian Kippnich ( $\square$ Kippnich_M@ukw.de)}

University Hospital Wurzburg: Universitatsklinikum Wurzburg

\section{Nora Schorscher}

Department of Anesthesiology, Intensive Care, Emergency- and Pain Medicine, Subsection Emergencyand Disaster Relief Medicine, University Hospital Wuerzburg

\section{Helmut Sattler}

Fire Department Wuerzburg, Office for Civil Defence and Fire Protection, City of Wuerzburg

\section{Uwe Kippnich}

Bavarian Red Cross, Headquarters, Munich

\section{Patrick Meybohm}

Department of Anesthesiology, Intensive Care, Emergency- and Pain Medicine, University Hospital

Wuerzburg

\section{Thomas Wurmb}

Department of Anesthesiology, Intensive Care, Emergency- and Pain Medicine, Subsection Emergencyand Disaster Relief Medicine, University Hospital Wuerzburg

\section{Original research}

Keywords: Mass casualty incident, Terrorism, Decontamination, Emergency Preparedness

Posted Date: March 4th, 2021

DOl: https://doi.org/10.21203/rs.3.rs-263244/v1

License: (c) (i) This work is licensed under a Creative Commons Attribution 4.0 International License. Read Full License

Version of Record: A version of this preprint was published at Journal of Emergency Management on January 1st, 2022. See the published version at https://doi.org/10.5055/jem.0650. 


\section{Abstract}

Background Chemical, Biological or Radio-nuclear (CBRN) incidents are a major challenge for emergency medical services and the involved hospitals. The challenge becomes even greater, if decontamination needs to be performed nearby or even within the hospital campus. To be prepared for such scenarios, the University Hospital Wuerzburg has developed a comprehensive and alternative CBRN response plan. Bullet points of the strategy are decontamination by Special Forces of the fire brigade and CBRN-experts of the Emergency Medical Services and the adaption to the hospitals spatial conditions. The focus of the presented study was to proof the practicability of the concept, the duration of the decontamination process and the temperature management during a full-scale exercise.

Methods On demand the decontamination unit can be put into operation within the roofed basement access zone in front of the emergency department. The entire decontamination area can be deployed $24 / 7$ by the hospitals technical staff. Fire and rescue services in adequate personal protective equipment are responsible for the decontamination process itself. The study was designed as full-scale exercise, which was documented by a camera team. The body temperature of the decontaminated Persons and the environment temerature was measured.

Results The entire process proofed to be successful. The decontamination area was ready for operation within 30 minutes. The decontamination of the four simulated patients took $5,5 \pm 0,6$ minutes (mean \pm SD) including handovers and undressing. 30 people have participated in the full-scale exercise. At the end of the decontamination process the temperature of the undressed upper body of the training patients was $27,25 \pm 1{ }^{\circ} \mathrm{C}\left(81,05 \pm 2{ }^{\circ} \mathrm{F}\right)($ mean $\pm \mathrm{SD})$, the water in the shower was about $35^{\circ} \mathrm{C}\left(95^{\circ} \mathrm{F}\right)$.

Conclusion The presented concept is comprehensive and simple for a best possible c care during CBRN incidents at hospitals. It ensures wet decontamination by Special Forces, while the technical requirements are created by the hospital.

\section{Background}

Mass casualty incidents with victims exposed to chemical, biological, radiological and nuclear (CBRN) materials are a major challenge for emergency medical services and the admitting hospitals. This is due to the initial lack of information about the toxic agent and the risk of secondary contamination for the rescue forces and healthcare personnel [1].

In most cases CBRN incidents occur in the context of industrial accidents, terrorist attacks or war [2]. Agents commonly used during terrorist attacks are acids, chlorine or chlorine compounds, riot control agents, cyanides and Bacillus anthracis [3]. Rapid evacuation and immediate decontamination are crucial factors, that influence medical outcome of the casualties [4]. Decontamination should be carried out directly on-scene by prehospital specialists [5]. The following are key elements of the process of decontamination: Prioritization, Undressing, Decontamination (wet or dry), Triage, Treatment [6, 7]. Wet decontamination seems to be most effective [8]. 
In certain cases, decontamination needs to be performed nearby or even due to hospital grounds: Selfpresenting casualties heading directly to healthcare facilities without first undergoing field decontamination $[9,10]$. Other reasons might be hostile sourroundings in which field decontamination is impossible, and patients will possibly arrive by ambulance at the hospital without decontamination.

It is obvious: hospitals need to be prepared for CBRN incidents [11].

Although hospitals are obliged to prepare for CBRN incidents, implementation is often associated with major difficulties. Emergency response plans must be drawn up. Staff, supply and space are the crucial factors, which need to be planned. Staff training in particular is complex and an appropriate level of knowledge and capability is difficult to maintain [9]. The use of personal protective equipment (PPE), the knowledge of the most common toxic substances, the appropriate measures and their application must be trained regularly.

Consumables and the techniques for decontamination must be kept ready to use. An adequate decontamination area should offer sufficient space to care for a large number of victims and must be close to the emergency department. The two pillars of this concept are the assembly of decontamination tents, which is always time consuming and complex and equipping staff with protective gear. The necessary material and supplies must be available in sufficient quantities and the personnel must be trained regularly in its application.

The University Hospital Wuerzburg, Germany, a tertiary-care hospital, has developed a comprehensive and alternative CBRN response plan. For managing CBRN-casualties wet decontamination was chosen as a key element. The technical realisation of the decontamination unit was adapted to the complex spatial conditions of the hospital. As a special feature, Special Forces of the fire brigade and CBRN-experts of the Emergency Medical Services (EMS) and not the hospital's staff carry out the entire decontamination process.

Aim of the presented study was to proof the ease of construction as well as functionality of the decontamination unit. Furthermore, the deployment of the Special Forces, the entire decontamination process, the temperature management, the cooperation with the ER staff as well as the handover of the patients were studied. The study was part of a full-scale exercise with rescue forces serving as simulated patients.

\section{Methods}

\section{Setting}

The University Hospital Wuerzburg is a level one trauma centre and the only tertiary care hospital of a northern Bavarian region with over 1.3 million inhabitants. The emergency department is located in the basement. Patients are admitted by ambulance services via a one way ramp which leads to a large underground access-zone in front of the emergency department. The possibility of deploying a 
conventional comprehensive decontamination lane with direct access to the emergency department is impossible. Due to these structural conditions, it was obligatory to find an appropriate alternative.

To start the planning process a multiprofessional and interdisciplinary expert committee was established. Hospital staff (emergency physicians, nurses, staff of technology and logistics) and the prehospital services (emergency medical services, professional fire brigade and CBRN-experts) were represented in this expert group. Based on spatial and tactical considerations, different areas of the entire hospital campus were evaluated. Staff and resource planning, technical implementation of the wet decontamination area, interface management, triage and patient care were identified as relevant items that needs to be considered and realized. Based on this evaluation process a concept was drafted, discussed, agreed upon and trialled with the help of a full-scale drill exercise.

\section{Technical Concept}

After evaluating multiple options, the roofed basement access zone in front of the emergency department has been chosen as the place for installing the decontamination area. Several parking spaces are separated by tarpaulins (black = contaminated, white = decontaminated) $($ Fig. 1). The tarpaulins, which are stored in the immediate vicinity, are attached to numbered hinges on the wall and columns of the parking lot. A decontamination shower with several showerheads is attached to an existing hot water pipe and fastened to the ceiling with chains on predefined hooks. This decontamination area can be deployed $24 / 7$ by the hospitals technical staff. The hospitals technical staff is available in about 15 minutes. The fire brigade completes the decontamination line with a conveyor belt for stretchers. Fire and rescue services in adequate protective equipment are responsible for the decontamination process itself and are supported by the hospitals technical staff (Fig. 2). The concept can be applied to both lying and walking patients.

\section{Staff Concept}

The number of staff and the personnel distribution including the required protective clothing is shown in Table 1.

\section{Study Design}

This pilot study was designed as a full-scale exercise. During the course of a scheduled field exercise four simulated patients went through the complete decontamination process (undressing, wet decontamination, handover). Professionals of the firefighter department represented the mock patients. CBRN specialists, emergency physicians, disaster manager, and technicians observed and evaluated the exercise. The start of the exercise was the briefing of the participating teams, the end was the handover of the fourth patient to the emergency department. A camera team filmed the entire exercise from different perspectives by using synchronized cameras. The film recordings were stocked with timestamps (minutes exactly). In retrospect, each sub-step could be traced. The project was presented to the local ethics committee of the University of Wuerzburg and was exempted from the need of ethical approval (reference number 20200720 01). 
The following parameters were the main time-variables of the study:

\begin{tabular}{|l|}
\hline Start of the exercise and start of decontamination area setup by hospital staff \\
\hline Arrival firefighters and EMS-CBR-Specialists \\
\hline Decontamination area ready for operation \\
\hline Patient 1: Handover from EMS and start decontamination \\
\hline Patient 1: End decontamination and handover to emergency room \\
\hline Patient 2: Handover from EMS and start decontamination \\
\hline Patient 2: End decontamination and handover to emergency room \\
\hline Patient 3: Handover from EMS and start decontamination \\
\hline Patient 3: End decontamination and handover to emergency room \\
\hline Patient 4: Handover from EMS and start decontamination \\
\hline Patient 4: End decontamination and handover to emergency room \\
\hline End of the exercise \\
\hline
\end{tabular}

\section{Temperature Measurement}

Multiple temperature measurements were taken. These included the temperature of the environment, the ground, the separated decontamination area, the spineboards, and the undressed upper body of the training patients (at the end of the decontamination process). For that an infrared thermometer was used (Testboy TV 325, Testboy GmbH, Germany). The measurement was performed three times per object and then the mean was calculated.

\section{Results}

\section{Chronological Course}

The decontamination area was ready for operation within 30 minutes. This included the provision of supplies within the emergency department, the arrival of the fire brigade and the EMS-CBR-Specialists as well as the technical setup and equipping the staff with protective equipment. The decontamination of a patient took four to six minutes including handovers and undressing. The exercise was finished with the handover of the fourth patient after a total of 60 minutes.

Table 2 shows the chronological course of the setup of the decontamination area and of the complete decontamination process of four lyingdown patients. 


\section{Temperature}

The exercise took place in January 2019. The outside temperature was $5^{\circ} \mathrm{C}\left(41^{\circ} \mathrm{F}\right)$. The temperature at the roofed access zone of the ambulances was $6-8^{\circ} \mathrm{C}\left(42,8^{\circ}-46,4^{\circ} \mathrm{F}\right)$, the temperature of the ground $4^{\circ} \mathrm{C}$ $\left(39,2^{\circ} \mathrm{F}\right)$. In the decontamination area the temperature was $18^{\circ} \mathrm{C}\left(64,4^{\circ} \mathrm{F}\right)$, the water in the shower was $35^{\circ} \mathrm{C}\left(95^{\circ} \mathrm{F}\right)$. The stretchers were between $20^{\circ} \mathrm{C}\left(68^{\circ} \mathrm{F}\right)$ and $22^{\circ} \mathrm{C}\left(71,6^{\circ} \mathrm{F}\right)$. At the end of the decontamination process the temperature of the undressed upper body of the training patients was 27,25 $\pm 1^{\circ} \mathrm{C}\left(81,05 \pm 2^{\circ} \mathrm{F}\right)($ mean $\pm \mathrm{SD})\left(\left(\right.\right.$ Patient $1: 28^{\circ} \mathrm{C}\left(82,4^{\circ} \mathrm{F}\right)$, Patient $2: 26^{\circ} \mathrm{C}\left(78,8^{\circ} \mathrm{F}\right)$, Patient $3: 28^{\circ} \mathrm{C}$ $\left(82,4^{\circ} \mathrm{F}\right)$, Patient $\left.4: 27^{\circ} \mathrm{C}\left(80,6^{\circ} \mathrm{F}\right)\right)$.

\section{Discussion}

Mass casualty incidents with victims exposed to chemical, biological, radiological and nuclear (CBRN) materials are rare and complex. If decontamination becomes necessary within the hospital ground (for safety reasons or because of the proximity to the damage site), there is a major risk that the hospital will soon be overwhelmed by patient flow and contamination with thetoxic agents.

Mortelmans et al showed that very few hospitals are prepared for such situations [12].

With the aim of eliminating this deficit for the University Hospital Wuerzburg, we developed a comprehensive concept for decontamination at the hospital site and verified it in a full-scale exercise.

We were able to show that the concept was easy to deploy. The technical elements and the structure were quickly implemented and without any problems. The staffing of the decontamination area took place without any difficulties. The entire decontamination process, from undressing to handover to the hospital staff, went smoothly and without relevant disturbances. The duration of the whole decontamination process was deemed acceptable.

Similar concepts have been published to ensure direct decontamination at hospitals. Brizio et al suggests that expensive facilities and equipment are not fundamental for a sufficient decontamination concept. Comparable to our concept, a decontamination area is established with simple materials (plastic sheeting, poles, plastic boxes etc.). However, the operation is operated by hospital staff. The access zone in front of the ER was chosen as the place for the decontamination area [13].

Markel et al. described the medical management of toxicological mass casualty events in Israel based on a distribution of hospital personnel to medical and non-medical personnel. While the non-medical staff is responsible for decontamination, the medical staff takes over the actual patient care [14]. Our approach goes even further. By having the decontamination carried out by the special forces, the hospital staff can fully concentrate on the subsequent medical treatment. The non-medical personnel remains available for further deployment after the setup of the decontamination area. 
Marzaleh et al emphasises the importance of interdisciplinarity in the development of a model for hospitals' preparedness in CBRN incidents. As in our study, multiple hospital staff worked together with prehospital experts and governmental institutions [15].

Temperature management plays an important role in wet decontamination. In the United States, the socalled Ladder-Pipe system is the most widespread concept for this. In the preclinical setting, but also in the "front of hospital" decontamination setting, a provisional shower is established using ladders from fire engines. These are used as framework for fire hoses. In a nationwide survey, $80 \%$ of the participants stated that they could not control the water temperature in this process. The estimated water temperature from the hydrants is $-1.1^{\circ} \mathrm{C}\left(30^{\circ} \mathrm{F}\right)$ to $26.1^{\circ} \mathrm{C}\left(79^{\circ} \mathrm{F}\right)$. As realized in our concept, tents with warm air and warm water, the use of buildings and thermal protection are recommended [5]. A water temperature of $32^{\circ} \mathrm{C}\left(90^{\circ} \mathrm{F}\right)$ to $40^{\circ} \mathrm{C}\left(104^{\circ} \mathrm{F}\right)$ is considered most suitable for wet decontamination [6]. The water in the shower in our decontamination area was about $35^{\circ} \mathrm{C}\left(95^{\circ} \mathrm{F}\right)$.

Another decisive factor for patient safety and for managing a CBRN mass casualty incident is the duration of decontamination. A duration of four minutes is specified for effective wet decontamination (30 seconds rinse of anterior skin and hair surfaces, 1 minute 30 seconds washing with a sponge, rotate the patient 90 degrees, 1 minute 30 seconds washing the back). These results are based on a study with human volunteers [6]. In further controlled studies of emergency decontamination even much shorter durations of wet decontamination (60 to 90 seconds) are considered sufficient [16, 17]. In practice, a much more distributed range of wet decontamination, especially for lying patients, can be assumed (few seconds to 17 minutes) $[5,18]$. In our study the decontamination took four to six minutes. This time frame demonstrates effectiveness without avoidable delays.

Both in practice and under operating conditions, the construction of a decontamination area is timeconsuming. Even the most simple system (ladder-pipe system) needs up to 20 minutes after the arrival of the emergency services until it is ready for operation [5]. In a published large-scale exercise (operation "DOWNPOUR"), in which different decontamination systems were compared, the exercise duration was described as 39,1 minutes (volunteer entered initial holding area to leaving rendez-vous point) [18]. In our setting the decontamination area was ready for operation after 30 minutes.

The limitations of the presented study should be acknowledged. Our investigation is a planned exercise with informed and prepared personnel. Also, the Special Forces (EMS and fire brigade) were immediately available. In real conditions the lead time might be much longer.

\section{Conclusion}

Decontamination of CBRN casualties is a major challenge. This is especially true for hospitals. Neither supplies nor the expertise is regularly available at hospitals for this purpose. Nevertheless, it is essential to prepare hospitals for such types of incidents. 
We have developed a comprehensive and simple concept for a tertiary care hospital that ensures decontamination by Special Forces, while the technical requirements are set up and by the hospital. The entire process proofed to be successful. This may encourage other hospitals to find their individual and simple solution for a complex problem.

\section{Declarations}

Ethics approval and consent to participate

The project was presented to the local ethics committee of the University of Wuerzburg and was exempted from the need of ethical approval (reference number 20200720 01). Professionals of the firefighter department represented the mock patients and have consented to do so.

\section{Consent for publication}

Not applicable.

\section{Availability of data and materials}

The dataset used and/or analysed during the current study are available from the corresponding author on reasonable request.

\section{Competing interests}

All authors declare that there are no competing interests. There was no support from any organization for the submitted work; no financial relationships with any organizations that might have an interest in the submitted work in the previous three years, no other relationships or activities that could appear to have influenced the submitted work.

\section{Funding}

There was no funding.

\section{Authors contribution}

MK, HS, UK and TW conceived the study and designed the trial. MK, NS, HS, UK, PM and TW supervised the conduct of the trial and data collection. MK and TW managed the data including quality control. MK, TW and PM provided statistical advice on study design and analyzed the data. MK drafted the manuscript, and all authors contributed substantially to its revision. MK and TW take responsibility for the paper as a whole.

\section{Acknowledgements}

Not applicable. 


\section{References}

1. Titus E, Lemmer G, Slagley J, Eninger R. A Review of CBRN Topics Related to Military and Civilian Patient Exposure and Decontamination. Am J Disaster Med. 2019; 14:137-49.

2. Baker D. Civilian exposure to toxic agents: emergency medical response. Prehosp Disaster Med. 2004;19:174-8.

3. Aydin B. Global Characteristics of Chemical, Biological, and Radiological Poison Use in Terrorist Attacks. Prehospital Disaster Med. 2020;35:260-6.

4. Leary AD, Schwartz MD, Kirk MA, Ignacio JS, Wencil EB, Cibulsky SM. Evidence-Based Patient Decontamination: An Integral Component of Mass Exposure Chemical Incident Planning and Response. Disaster Med Public Health Prep. 2014;8:260-6.

5. Power S, Symons C, Carter H, Jones E, Amlôt R, Larner J, et al. Mass Casualty Decontamination in the United States: An Online Survey of Current Practice. Health Secur. 2016;14:226-36.

6. Chilcott RP, Mitchell H, Matar H. Optimization of Nonambulant Mass Casualty Decontamination Protocols as Part of an Initial or Specialist Operational Response to Chemical Incidents. Prehosp Emerg Care. 2019;23:32-43.

7. Chilcott RP, Larner J, Matar H. UK's initial operational response and specialist operational response to CBRN and HazMat incidents: a primer on decontamination protocols for healthcare professionals. Emerg Med J. 2018;36:117-23.

8. Amlôt R, Carter H, Riddle L, Larner J, Chilcott RP, Oudejans L. Volunteer trials of a novel improvised dry decontamination protocol for use during mass casualty incidents as part of the UK'S Initial Operational Response (IOR). PLOS ONE. 2017;12:e0179309.

9. Razak S, Hignett S, Barnes J. Emergency Department Response to Chemical, Biological, Radiological, Nuclear, and Explosive Events: A Systematic Review. Prehospital Disaster Med. 2018;33:543-9.

10. Koenig KL, Boatright CJ, Hancock JA, Denny FJ, Teeter DS, Kahn C, et al. Health care facility-based decontamination of victims exposed to chemical, biological, and radiological materials. Am J Emerg Med. 2008;26:71-80.

11. Kako M, Hammad K, Mitani S, Arbon P. Existing Approaches to Chemical, Biological, Radiological, and Nuclear (CBRN) Education and Training for Health Professionals: Findings from an Integrative Literature Review. Prehospital Disaster Med. 2018;33:182-90.

12. Mortelmans LJM, Gaakeer MI, Dieltiens G, Anseeuw K, Sabbe MB. Are Dutch Hospitals Prepared for Chemical, Biological, or Radionuclear Incidents? A Survey Study. Prehospital Disaster Med. 2017;32:483-91.

13. Brizio A, Hubert J-C, Hennequin B, Bouchez J, Kouka M-C. Swift and Low-Cost Surge in Chemical Threat Response: Is It Possible? The Experience of a French Hospital. Disaster Med Public Health Prep. 2018;12:649-56.

14. Markel G, Krivoy A, Rotman E, Schein O, Shrot S, Brosh-Nissimov T, et al. Medical Management of Toxicological Mass Casualty Events. 2008;10:6. 
15. Ahmadi Marzaleh M, Rezaee R, Rezaianzadeh A, Rakhshan M, Haddadi G, Peyravi M. Developing a Model for Hospitals' Emergency Department Preparedness in Radiation and Nuclear Incidents and Nuclear Terrorism in Iran. Bull Emerg Trauma. 2019;7:300-6.

16. Larner J, Jones DR, Price SC, Chilcott RP. Modified static diffusion cells for decontamination modelling. 2010; 278:351-352

17. Amlôt R, Larner J, Matar H, Jones DR, Carter H, Turner E, et al. Comparative analysis of showering protocols for mass-casualty decontamination. Prehosp Disaster Med. 2010;25:435-9.

18. Chilcott RP, Larner J, Durrant A, Hughes P, Mahalingam D, Rivers S, et al. Evaluation of US Federal Guidelines (Primary Response Incident Scene Management [PRISM]) for Mass Decontamination of Casualties During the Initial Operational Response to a Chemical Incident. Ann Emerg Med. 2019;73:671-84.

\section{Tables}


Table 1

Personnel concept including protective clothing for the wet decontamination process

\begin{tabular}{|c|c|c|}
\hline $\begin{array}{l}\text { Section of the } \\
\text { decontamination concept }\end{array}$ & Personnel & Protective clothing \\
\hline \multirow[t]{2}{*}{ Head of Operations } & 1 Emergency physician & \multirow[t]{2}{*}{ None specific } \\
\hline & $\begin{array}{l}1 \text { On-site commander (fire } \\
\text { brigade or EMS) }\end{array}$ & \\
\hline \multirow[t]{2}{*}{ Setup and technical support } & 6 Hospital technical staffs & \multirow[t]{2}{*}{ None specific } \\
\hline & $\begin{array}{l}6 \text { Firefighters/EMS-CBR- } \\
\text { Specialists }\end{array}$ & \\
\hline \multirow{4}{*}{$\begin{array}{l}\text { Handover and transfer from } \\
\text { EMS }\end{array}$} & 1 Emergency physician* & Full body protective suit \\
\hline & \multirow{3}{*}{$\begin{array}{l}4 \text { Firefighters/EMS-CBR- } \\
\text { Specialists }\end{array}$} & Safety goggles \\
\hline & & FFP3-Mask \\
\hline & & Protective gloves \\
\hline \multirow[t]{3}{*}{ Wet decontamination } & \multirow{3}{*}{$\begin{array}{l}3 \text { Firefighters/EMS-CBR- } \\
\text { Specialists }\end{array}$} & Full body protective suit \\
\hline & & $\begin{array}{l}\text { Full face respiratory mask with } \\
\text { breathing filter }\end{array}$ \\
\hline & & Protective gloves \\
\hline \multirow{4}{*}{$\begin{array}{l}\text { Handover and transfer to } \\
\text { Emergency Room }\end{array}$} & \multirow[t]{4}{*}{4 Emergency nurses } & Protective gown \\
\hline & & Safety goggles \\
\hline & & FFP3-Mask \\
\hline & & Disposable gloves (two pairs) \\
\hline Reserve & $\begin{array}{l}4 \text { Firefighters/EMS-CBR- } \\
\text { Specialists }\end{array}$ & None specific \\
\hline
\end{tabular}

$($ EMS $=$ Emergency Medical Services; $\mathrm{CBR}=$ Chemical, Biological or Radio-nuclear; FFP = Filtering Face Piece)

*The task of the emergency physician is to prioritise decontamination. 
Table 2

Chronological course of the setup of the decontamination area and the decontamination of four lyingdown patients

\begin{tabular}{|ll|}
\hline Exercise procedure & Timeline \\
\hline Start of the exercise and start of decontamination area setup by hospital staff & $\mathrm{t}=0$ \\
\hline Arrival firefighters and EMS-CBR-Specialists & $\mathrm{t}=15$ minutes \\
\hline Decontamination area ready for operation & $\mathrm{t}=30$ minutes \\
\hline Patient 1: Handover from EMS and start decontamination & $\mathrm{t}=34$ minutes \\
\hline Patient 1: End decontamination and handover to emergency room & $\mathrm{t}=40$ minutes \\
\hline Patient 2: Handover from EMS and start decontamination & $\mathrm{t}=41$ minutes \\
\hline Patient 2: End decontamination and handover to emergency room & $\mathrm{t}=46$ minutes \\
\hline Patient 3: Handover from EMS and start decontamination & $\mathrm{t}=46$ minutes \\
\hline Patient 3: End decontamination and handover to emergency room & $\mathrm{t}=52$ minutes \\
\hline Patient 4: Handover from EMS and start decontamination & $\mathrm{t}=55$ minutes \\
\hline Patient 4: End decontamination and handover to emergency room & $\mathrm{t}=60$ minutes \\
\hline End of the exercise & $\mathrm{t}=60$ minutes \\
\hline
\end{tabular}

\section{Figures}




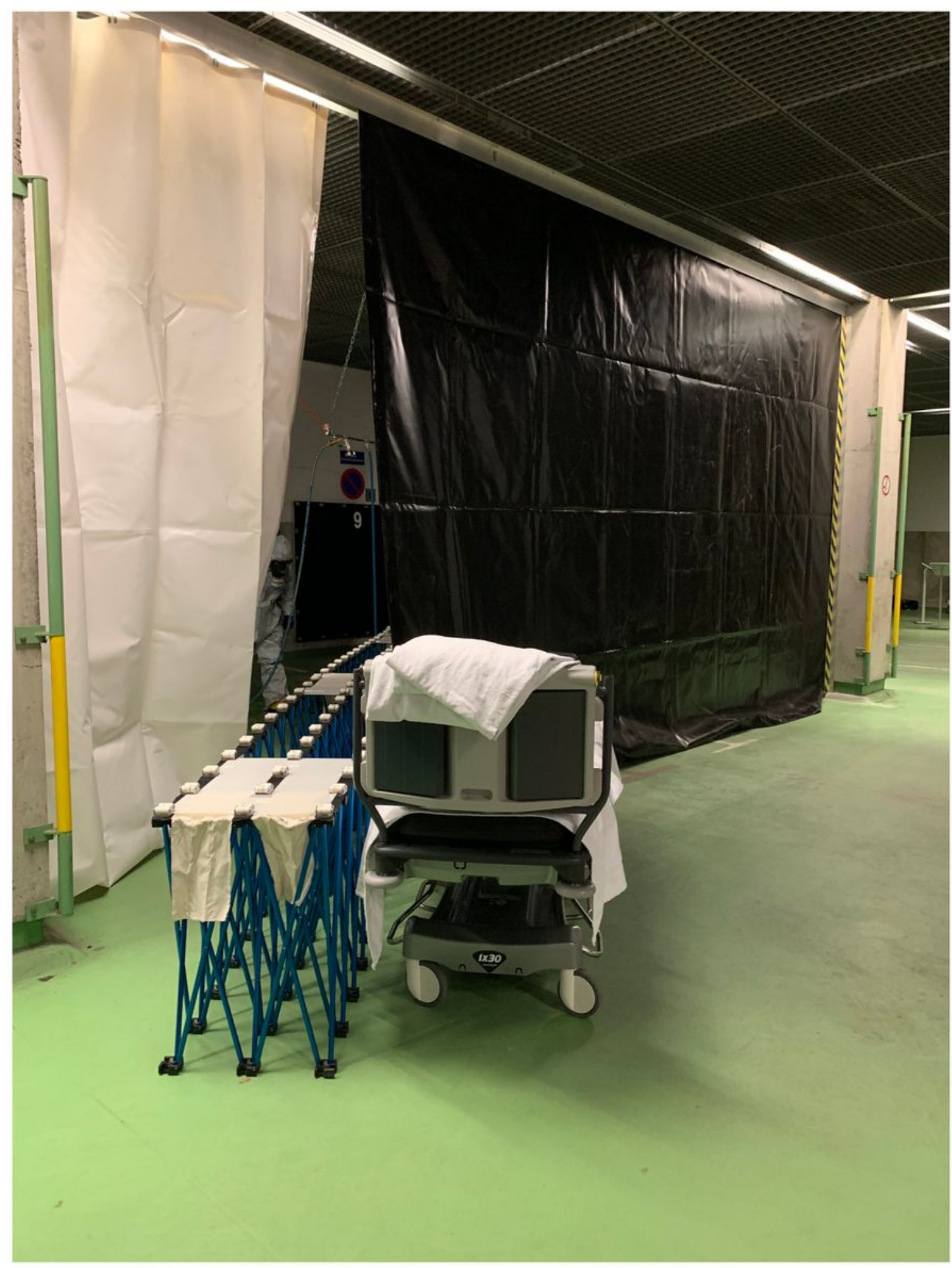

Figure 1

Decontamination area in the roofed basement access zone in front of the emergency room with parking spaces separated by tarpaulins $($ black $=$ contaminated, white $=$ decontaminated $)$ 


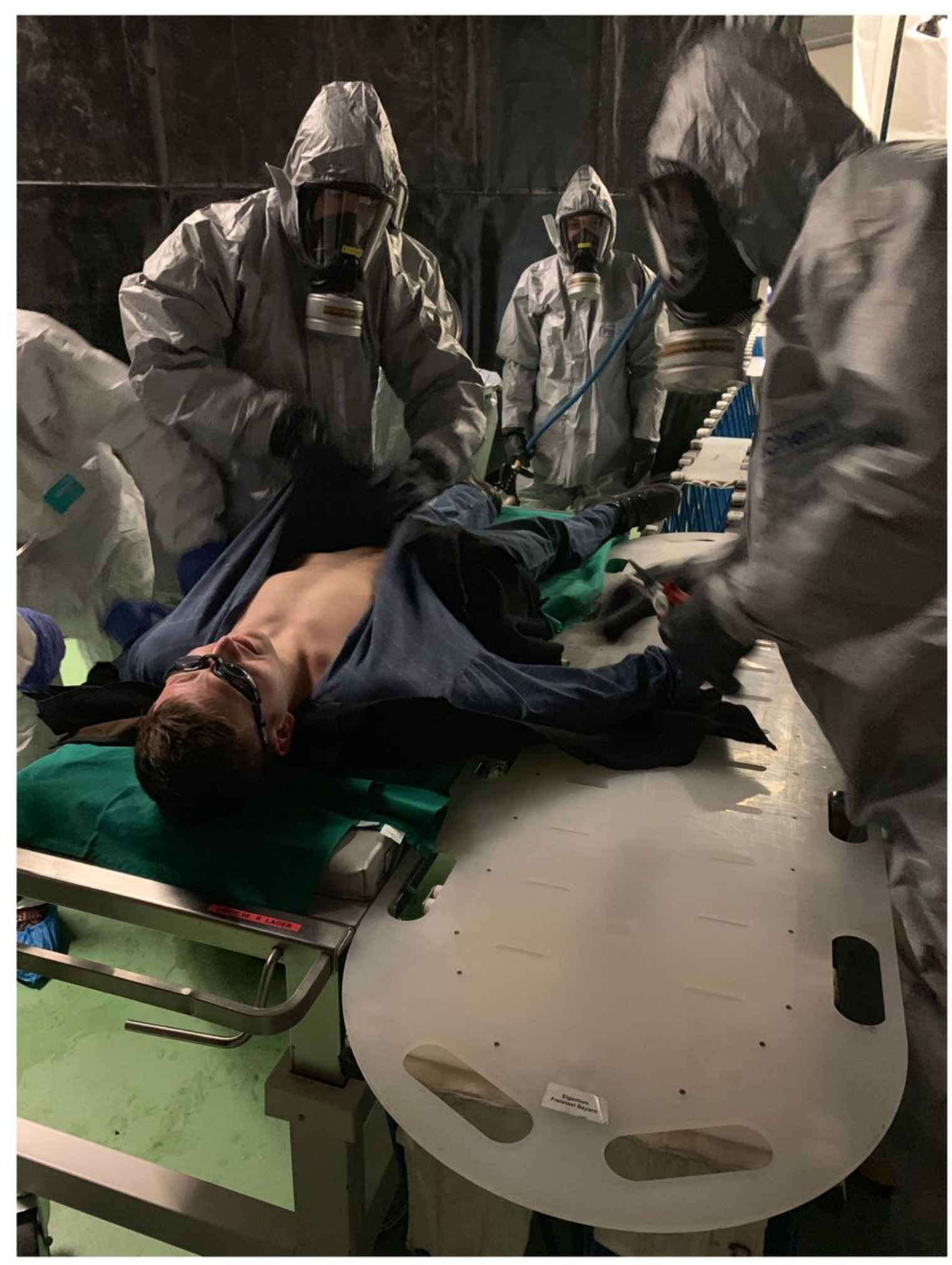

Figure 2

Wet decontamination by fire and rescue services in adequate protective equipment 